ARTICLE

Received 26 May 2016 | Accepted 7 Sep 2016 | Published 26 Oct 2016

DOI: $10.1038 /$ ncomms13144

OPEN

\title{
The uronic acid content of coccolith-associated polysaccharides provides insight into coccolithogenesis and past climate
}

\author{
Renee B.Y. Lee ${ }^{1,2, \star}$, Despoina A.I. Mavridou ${ }^{3,4, \star}$, Grigorios Papadakos ${ }^{4}$, Harry L.O. McClelland ${ }^{1}$ \\ $\&$ Rosalind E.M. Rickaby ${ }^{1}$
}

Unicellular phytoplanktonic algae (coccolithophores) are among the most prolific producers of calcium carbonate on the planet, with a production of $\sim 10^{26}$ coccoliths per year. During their lith formation, coccolithophores mainly employ coccolith-associated polysaccharides (CAPs) for the regulation of crystal nucleation and growth. These macromolecules interact with the intracellular calcifying compartment (coccolith vesicle) through the charged carboxyl groups of their uronic acid residues. Here we report the isolation of CAPs from modern day coccolithophores and their prehistoric predecessors and we demonstrate that their uronic acid content (UAC) offers a species-specific signature. We also show that there is a correlation between the UAC of CAPs and the internal saturation state of the coccolith vesicle that, for most geologically abundant species, is inextricably linked to carbon availability. These findings suggest that the UAC of CAPs reports on the adaptation of coccolithogenesis to environmental changes and can be used for the estimation of past $\mathrm{CO}_{2}$ concentrations.

\footnotetext{
${ }^{1}$ Department of Earth Sciences, University of Oxford, Oxford OX1 3AN, UK. ${ }^{2}$ School of Biological Sciences, University of Reading, Whiteknights, Reading RG6 6UB, UK. ${ }^{3}$ MRC Centre for Molecular Bacteriology and Infection, Department of Life Sciences, Imperial College London, London SW7 2DD, UK. ${ }^{4}$ Department of Biochemistry, University of Oxford, Oxford OX1 3QU, UK. * These authors contributed equally to this work. Correspondence and requests for materials should be addressed to R.B.Y.L. (email: r.b.y.lee@reading.ac.uk).
} 
C alcifying coccolithophores form their intricate calcite structures within Golgi-derived intracellular vesicles and under the strict control of several components, such as an insoluble organic baseplate and water-soluble acidic polysaccharides $^{1-3}$. The latter are known as coccolith-associated polysaccharides (CAPs) and they act as an organic framework for coccolith formation; they provide binding sites for the mineral components of calcification, nucleate specific crystallographic faces and dictate the rate of calcite precipitation in vivo and in vitro ${ }^{4-7}$. The ability to execute their role lies within their chemical composition ${ }^{4}$. CAPs are mainly composed of neutral monosaccharides complemented by two acidic moieties, sulphate esters and uronic acids ${ }^{8}$. It has been shown that it is uronic acids that provide the essential, negatively charged carboxyl groups that preferentially bind the calcium cations $\left(\mathrm{Ca}^{2+}\right)$ (ref. 4) and initiate calcification.

CAPs are structurally and functionally diverse across different species of coccolithophores. Three CAPs are involved in the complex regulation of coccolithogenesis in Pleurochrysis carterae 9 as opposed to one in Emiliania huxleyi ${ }^{6}$. Their biochemical composition has also been shown to vary across species ${ }^{10}$ and morphologically distinct strains of E. huxleyi ${ }^{6,11}$. In fact, this property was successfully exploited for antisera production that have been used for classifying E. huxleyi morphotypes $\mathrm{A}$ and $\mathrm{B}^{12}$.

CAPs do not single-handedly regulate coccolith biomineralization. Instead, they work in concert with the internal environment of the coccolith vesicle. Giuffre et al. ${ }^{13}$ demonstrated that the combination of polysaccharide chemistry with compartmental saturation state determines the kinetics of calcite nucleation. This means that CAP diversity is likely to be the adaptive outcome to a species-specific internal saturation state. This saturation state, given an abundance in calcium, and in species with a weak or absent carbon concentrating mechanism, is linked to the availability of carbon in the extracellular environment.

In this multidisciplinary study, we aim to elucidate the role of CAPs in dictating the morphological variation of coccoliths in relation to their adaptive strategy to changing $\mathrm{CO}_{2}$ concentrations over the millennia. For this reason, we sampled across a wide range of cultured strains and species and isolated CAPs from several sediment samples containing fossil coccoliths. In this way, we were able to shed light on the adaptation of CAPs through time and to propose their potential use as a species/strain biomarker and, more importantly, as a potential tool for inferring past environmental change.

\section{Results}

Coccolithophore samples from past and present. In order to probe the diversity of CAPs, we cultured four extant species of coccolithophores. These are ultrastructurally and physiologically diverse organisms, present in a variety of habitats and either have identifiable ancestors or are themselves abundant in the geological record. Coccolithus pelagicus ssp. braarudii (family Coccolithaceae) (Fig. 1g) and Calcidiscus leptoporus (family Calcidiscaceae) (Fig. 1f) are two of the largest and most heavily calcifying species from the order Coccolithales. This order diverged from its last common ancestor with the Isochrysidales after the P/Tr boundary ( $\sim 243 \mathrm{Ma}$; ref. 14$)$, and has prevailed throughout the early Cenozoic, only to be marginalized in present-day oceans ${ }^{15}$. Gephyrocapsa oceanica (Fig. 1d,e) and E. huxleyi (family Noëlaerhabdaceae) (Fig. 1a-c), were selected from the geologically younger order Isochrysidales. The genus Gephyrocapsa first appeared in the late Pliocene $(\sim 3.5 \mathrm{Ma})$ and rose to dominance in the Early Pleistocene ${ }^{16}$. Its descendant species, E. huxleyi (at $\sim 250 \mathrm{ka}$ ), has since become the most abundant coccolithophore in the modern ocean ${ }^{1}$. Strains of
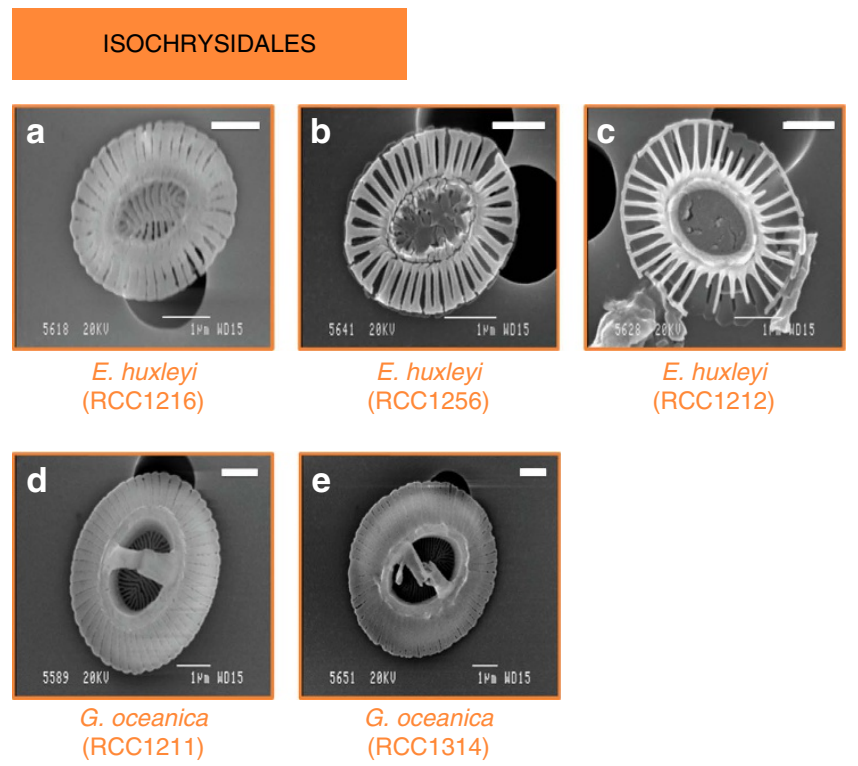

COCCOLITHALES

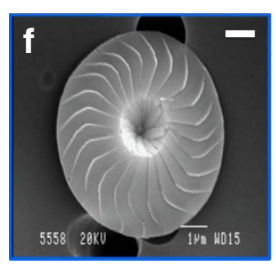

C. leptoporus (RCC1129)

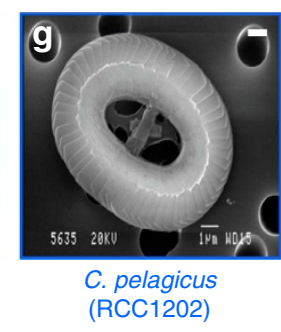

Figure 1 | Scanning electron micrographs of coccoliths from live species. (a) Emiliania huxleyi (RCC1216, morphotype R); (b) Emiliania huxleyi (RCC1256, morphotype A); (c) Emiliania huxleyi (RCC1212, morphotype B); (d) Gephyrocapsa oceanica (RCC1211) (this strain was supplied from the culture collection as Emiliania huxeyi, morphotype B/C and was identified as G. oceanica in this study); (e) Gephyrocapsa oceanica (RCC1314);

(f) Calcidiscus leptoporus (RCC1129); (g) Coccolithus pelagicus ssp. braarudii (RCC1202). Scale bars (top right), $1 \mu \mathrm{m}$.

E. huxleyi representing three distinct morphotypes with varying degrees of calcification as well as subtle ultrastructural differences, were selected for this study (Fig. 1a-c, Supplementary Table 1). The degree of coccolith calcification of the E. huxleyi morphotypes can be arranged in the order of B (Fig. 1c) $<A$ (Fig. 1b) $<\mathrm{R}$ (Fig. 1a) based on morphometric observations ${ }^{17-19}$.

Recently, Sand et al. ${ }^{20}$ demonstrated that CAPs are preserved in chalk deposits from the Maastrichtian (65-70 Ma). These ancient extracts were still active and displayed the characteristic properties of known $\mathrm{CAPs}^{5,20}$. For this reason we wanted to analyse the properties of CAPs not only from cultured samples but also from fossil coccoliths. We obtained sedimentary material from the Upper Pleistocene $(\sim 107 \mathrm{ka})$, as well as the geologically older Serravalian (12.4-13.6 Ma), Langhian ( $14.5 \mathrm{Ma})$, Burdigalian $(\sim 16 \mathrm{Ma})$, Campanian $(76-80 \mathrm{Ma})$, Late Cenomanian $(\sim 94 \mathrm{Ma})$, Tithonian $(\sim 150 \mathrm{Ma})$ and Early Toarcian ( $\sim 180 \mathrm{Ma}$ ) (Supplementary Table 2$)$. The fine-fraction from the Upper Pleistocene was separated into mono-specific coccolith fractions; the three size-delimited fractions retained for analysis consist of the C. pelagicus fraction $(10-12 \mu \mathrm{m})$, the Noëlaerhabdaceae fraction $(0-3 \mu \mathrm{m})$ and the bulk coccolith fraction $(<12 \mu \mathrm{m})$, which contains all contemporaneous 
coccoliths from this site (cross-polarized micrographs of these fractions are shown in Supplementary Fig. 1a). By mass of calcite, over $90 \%$ of the coccoliths in the $10-12 \mu \mathrm{m}$ fraction were C. pelagicus and $\sim 30 \%$ of the total calcite across all size fractions was foraminiferal debris. The quality of separation in terms of relative numerical abundance by species is summarized in Supplementary Table 3. Samples from the Serravalian, Langhian and Burdigalian are almost mono-specific coccolith fractions with coccolith sizes larger than $8 \mu \mathrm{m}$, which predominantly consist of Discoaster spp. and C. pelagicus (a representative cross-polarized micrograph is shown in Supplementary Fig. 1b). Samples from the Campanian, Late Cenomanian, Tithonian and Early Toarcian were analysed in bulk. Fossils from the Late Cenomanian and Early Toarcian mainly consist of the extinct Watznaueria spp. and Crepidolithus spp., respectively while samples from the Campanian and Tithonian also predominantly consist of larger coccolithophores (predecessors of the modern Coccolithales).

Isolation and biochemical characterization of CAPs. We successfully isolated the CAPs from several cultured samples and also from sediment samples dating back to $\sim 180 \mathrm{Ma}$ (Supplementary Table 4 ) and initially tested the extracts for the presence of protein. We subjected the CAPs to native polyacrylamide gel electrophoresis (PAGE) and stained the gel with Coomassie Brilliant Blue R-250 that would stain any protein molecules, however, no bands were visible. Similarly, no protein was detected by Bradford assay. Although these tests suggest the absence of protein molecules in our extracts, we cannot preclude the role of proteins in coccolith biomineralization ${ }^{6,21}$. Subsequently, we stained the gel with Alcian blue, a dye that selectively complexes the carboxyl groups of acidic polysaccharides (Fig. 2a). A single band was detected for each extract (indicated by an orange or blue arrowhead in Fig. 2a) and this demonstrated the isolation of one CAP per strain/species. Although all CAPs migrated as a single band, we observed a significant variation in their electrophoretic mobility (Fig. 2a). We subjected the same samples to denaturing sodium dodecyl sulfate (SDS)-PAGE analysis (Supplementary Fig. 2). The presence of the anionic detergent SDS imparts a uniform negative charge on the CAPs during SDS-PAGE analysis so that the polysaccharides migrate only according to their size. Since the migration pattern of the CAPs is identical during PAGE and SDS-PAGE analysis (Supplementary Fig. 2) we can conclude that the observed migration pattern of CAPs during PAGE-analysis is not affected by their charged (sulfonic and uronic acid) residues. Therefore, there is a true difference in the size of our isolated CAPs, which concurs with previous reports ${ }^{6,10}$.

CAPs from cultured and fossil samples were also subjected to reverse-phase high-performance liquid chromatography (RP-HPLC) to confirm their identity as acidic polysaccharides (Supplementary Fig. 3a). Apple pectin (polygalacturonic acid), a known acidic polysaccharide that has been shown to promote calcification ${ }^{13}$, was also subjected to RP-HPLC analysis as a positive control (Supplementary Fig. 3b). We found that all tested CAPs have the same polarity as apple pectin because they eluted in the same solvent gradient range (marked by the grey shaded area in Supplementary Fig. 3a,b). This confirmed that our extracts are indeed acidic polysaccharides. Interestingly, we also observed that our CAPs, as well as pectin, elute as multiple peaks during RP-HPLC analysis. This demonstrates the occurrence of several potential spatial configurations (conformers) of each CAP molecule. Size-exclusion chromatography showed the same; a single but broad peak was observed for each extract confirming the presence of more than one conformer for each extracted CAP (see the representative example of the analysis of the G. oceanica a

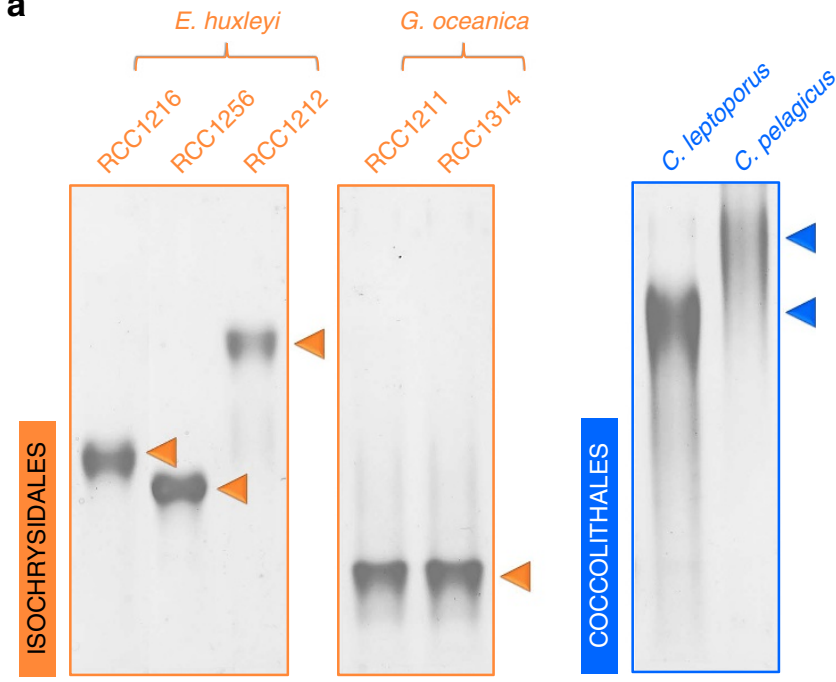

b

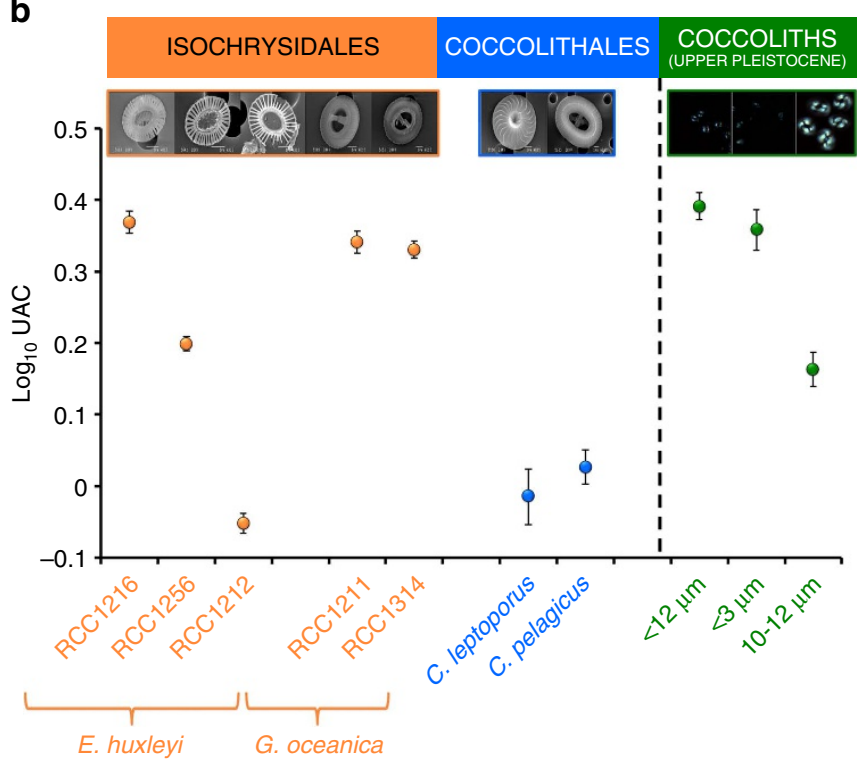

Figure 2 | The size and uronic acid content of coccolith-associated acidic polysaccharides provide a species-specific signature.

(a) Polyacrylamide gel electrophoresis (PAGE) of CAPs isolated from cultured coccolithophores. Analysis was carried out using $4 \mu \mathrm{g}$ of each coccolith-associated acidic polysaccharide (CAP) on a $12 \%$ polyacrylamide gel. CAPs were stained with Alcian Blue. One CAP was isolated from each species/strain; this is obvious from the presence of a single band in each lane (indicated by an orange or blue arrowhead). (b) Variation in the uronic acid content (UAC) of CAPs extracted from cultured coccolithophores and fossil coccoliths. The UAC of CAPs from present day species/strains and size-separated fractions from the ODP1123 geological site (Upper Pleistocene, South Pacific Ocean) is plotted on a logarithmic scale. Error bars represent the s.d. between two independent replicates. The exact average UAC values for each sample are given in Supplementary Table 6.

RCC1314 CAP in Supplementary Fig. 3c; the peak of interest is marked by the grey shaded area). It is important to note that identical amounts of CAPs from cultured and fossil samples gave nearly identical traces, in shape, intensity and elution time, during RP-HPLC analysis (Supplementary Fig. 3a). Had degradation of the CAPs that we extracted from fossils coccoliths taken place, we would have recorded very different elution profiles for these 
extracts compared with the CAPs that we isolated from live organisms. Therefore, we can conclude that the CAPs we isolated from fossil samples are intact and very similar in chemical composition to the CAPs from modern cultures containing the same species/strains. Preservation of CAPs in fossils is also in agreement with previous reports of CAP extraction from sediments $^{20,22}$. We note that PAGE (or SDS-PAGE) and RP-HPLC analysis, although overall very informative, are mostly qualitative characterization methods. For a more accurate measure of the relative size differences between different CAPs and of the exact degree of preservation of CAPs extracted from fossil samples, size-exclusion chromatography, followed by reduction of the samples and mass spectrometry would probably be advantageous.

UAC of CAPs as a species-specific biomarker. By providing the negatively charged carboxyl groups that interact with the positively charged $\mathrm{Ca}^{2+}$ in the coccolith vesicle, uronic acid moieties in CAPs are crucial in dictating the overall calcite nucleation and precipitation rates ${ }^{6}$. For this reason, we measured the uronic acid content (UAC) for all our extracts from cultured and fossil samples using a modified carbazole- $\mathrm{H}_{2} \mathrm{SO}_{4}$ assay ${ }^{23}$ (Fig. 2b, Supplementary Table 6). Our results show that the UAC varies significantly between species/strains and this fluctuation can be successfully used for biochemical distinction between strains of E. huxleyi and across species of coccolithophores (see the example mentioned in Supplementary Table 1). The UAC-species relationship is conserved in CAPs isolated from sediments, with the Coccolithales (10-12 $\mu \mathrm{m}$ fraction) consistently yielding lower UAC than the Isochrysidales $(<3 \mu \mathrm{m}$ and dominating the mixed $<12 \mu \mathrm{m})$. Thus, based on the data presented in Fig. 2b, the UAC of CAPs can be used to complement existing tools for diagnosing taxonomic affinities when morphological and DNA preservation is poor or ambiguous $^{24,25}$. Furthermore, the UAC is a sensitive enough biomarker, able to distinguish even between different clonal strains of E. huxleyi ${ }^{11}$. This metric could be used for determining clonal distribution and detecting population shifts in the environment, which is key to the understanding of the adaptive potential of E. huxleyi populations and their impact on biogeochemical cycles.

UAC of CAPs and saturation state of the coccolith vesicle. According to Fig. 2b, the UAC of CAPs that were isolated from Isochrysidales is directly proportional to their recorded degree of calcification as depicted in our scanning electron microscopy (SEM) images (Fig. 1a-e). In strains of E. huxleyi, the CAP of RCC1216 (morphotype R, Fig. 1a), which is frequently described as heavily calcifying, has the highest UAC, whereas the lightly calcified coccoliths of RCC1212 (morphotype B, Fig. 1c) have the lowest. The same correlation can be made for G. oceanica; both strains we tested have a high UAC (Fig. 2b) and are heavily calcifying (Fig. 1d,e). However, an inverse relationship is observed in Coccolithales, where low UAC did not result in a lightly calcified coccolith (Figs 1f,g and 2b). This observation seems paradoxical at first but it can be explained if one takes into account the charge density of CAPs in relation to the saturation state of the coccolith vesicle and its effect on the nucleation rate of calcite. It is important to remember that, according to Giuffre et $a{ }^{13}{ }^{13}$, substrates rich in carboxyl functional groups (high UAC in the case of CAPs) promote fast nucleation rates at high intracellular supersaturation, whereas at low saturation states, substrates with lower charge density (low UAC) promote faster rates of nucleation. Unfortunately, due to the transient nature of the coccolith vesicle, there is little information pertaining to its chemical state during coccolithogenesis ${ }^{26}$. More specifically, in order to generate an absolute measure of internal saturation state we would need to know the $\mathrm{pH}$ and the concentration of $\mathrm{Ca}^{2+}$ in the coccolith vesicle during calcification; both these parameters are currently unknown. However, by considering the published data on several contributing factors known to affect the internal saturation state (for example, the utilization rates of calcium and carbon, the supply of carbon and the size of the organism), we can predict if a coccolithophore is likely to have a high or low saturation state in its coccolith vesicle.

In Supplementary Table 5 we present all the published information on parameters that are known to affect the internal saturation state of coccolithophores. The high utilization rate of calcium over carbon (given by the high PIC/POC, where PIC stands for particulate inorganic carbon and POC for particulate organic carbon), the slow $\mathrm{CO}_{2}$ diffusion (given by the low $\mathrm{SA} / V$, where SA is the surface area and $V$ is the volume of the coccolithophore) and the large size of the Coccolithales like $C$. pelagicus, point towards a low internal saturation state of this order. This is further supported by the lack of any evidence that the Coccolithales have a carbon concentrating mechanism and the fact that they are generally characterized by a low internal dissolved inorganic carbon pool ${ }^{27,28}$. Therefore, their measured low UAC (Fig. 2b) correlates very well with efficient nucleation at lower internal saturation state that results in a highly calcified coccolith (Fig. 1f,g). On the other hand, Isochrysidales have a lower utilization rate of calcium over carbon (lower PIC/POC), they are significantly smaller (approximately fivefold smaller in diameter) (Supplementary Table 5) and they have a high SA/ $V$ ratio, which means that they acquire $\mathrm{CO}_{2}$ from their environment much more efficiently than the Coccolithales. In addition, there is evidence for a carbon concentrating mechanism in the ability of members of this order to utilize their dissolved inorganic carbon to increase their internal saturation state ${ }^{29-33}$. All the above contribute towards a high saturation state in the coccolith vesicle of Isochrysidales, which means that optimal calcification is achieved by high charge densities (high UAC for the heavily calcifying species/strains as shown in Fig. 2b). We can, therefore, conclude that by altering their polysaccharide charge density, coccolithophores are able to finetune their calcite precipitation process to varying degrees of internal supersaturation and that this adaptation, in most cases, allows them to achieve optimal calcification.

UAC of CAPs and environmental $p \mathrm{CO}_{2}$. Characterization of CAPs extracted from the geological record lends further support to this proposal. Isochrysidales and Coccolithales have distinct geological histories with regard to cell size ${ }^{15,34,35}$. Estimates based on coccolith morphometrics suggest that the cell size of Coccolithus spp. and Calcidiscus spp. remain largely unchanged throughout the Cenozoic decline in $\mathrm{pCO}_{2}$ (ref. 36). We found that CAPs extracted from older Coccolithale-containing fossil samples from the greenhouse high $p \mathrm{CO}_{2}$ world have a high UAC (Fig. 3a, Supplementary Table 7; points 1-6), which was beneficial for calcification when carbon availability and the internal carbon pool of the cell was high. However, in order to sustain calcification as their internal pool diminished during the decline in $p \mathrm{CO}_{2}$ and in the absence of evolution of a strong carbon concentrating mechanism, more recent Coccolithales reduced their CAP charge in favour of retaining a larger cell size (Fig. 3a, Supplementary Table 7; points 7-13). Isochrysidales, on the other hand, have been shown to diminish their size through time as a form of adaptation to declining $p \mathrm{CO}_{2}$ (ref. 37). As such, we found that they have overall a relatively high UAC that promotes calcification in a consistently highly saturated environment (Fig. 2b, Supplementary Table 6). 
a
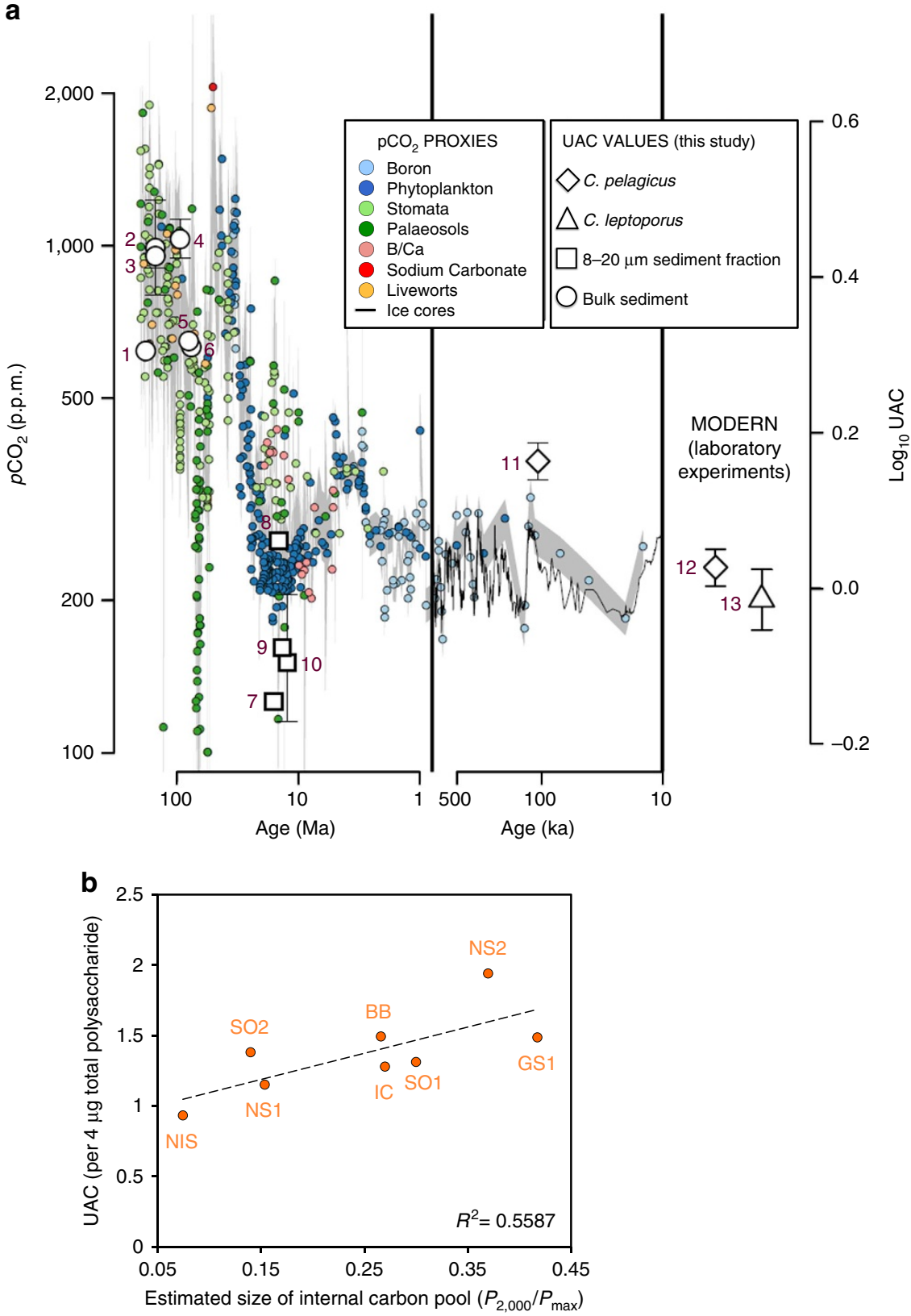

Figure 3 | The uronic acid content of coccolith-associated acidic polysaccharides correlates with the size of the internal carbon pool of the coccolithophore. (a) Average uronic acid content (UAC) values of coccolith-associated acidic polysaccharides (CAPs) isolated from modern Coccolithales (points 12 and 13), C. pelagicus from the Upper Pleistocene sediments (point 11) or the Neogene sediments (points 7-10) and prehistoric predecessors of the Coccolithales from bulk fossil samples (points 1-6). The UAC values are plotted alongside proxy-reconstructed atmospheric $p \mathrm{CO}_{2}$ for the past $200 \mathrm{Ma}^{2}$ and ice core $\mathrm{CO}_{2}$ records. The grey lines represent the range of $p \mathrm{CO}_{2}$ as estimated from proxies and ice core data (at $1 \sigma$ confidence level). Proxies were compiled from Royer ${ }^{44}$, Park and Royer ${ }^{45}$, Beerling and Royer ${ }^{46}$ and Hönisch et al. ${ }^{47}$; ice core $\mathrm{CO}_{2}$ records were obtained from Lüthi et al. ${ }^{48}$. Details on the cultured and fossil samples can be found in Supplementary Tables 1 and 2, respectively and the exact UAC values for each point are given in Supplementary Table 7. Error bars represent the s.d. between two independent replicates. (b) UAC (per $4 \mu \mathrm{g}$ total CAP) of the CAPs extracted from recently isolated strains of Emiliania huxleyi (morphotype $A$ and $B / C$ ) versus the estimated size of the intracellular carbon pool (inferred from the ratio of photosynthetic rates at near ambient conditions of $2,000 \mu \mathrm{mol} \mathrm{kg}{ }^{-1}$ dissolved inorganic carbon $\left(P_{2,000}\right)$ and the maximum rate of photosynthesis $\left.\left(P_{\text {max }}\right)\right)($ as detailed in Rickaby et al. ${ }^{11}$ ). Details on the $E$. huxleyi strains (abbreviated in orange on the graph) and the exact $U A C, P_{2,000}$ and $P_{\max }$ values for each point are given in Supplementary Table 8.

The UAC values of CAPs we extracted from recently isolated E. huxleyi strains from different locations provide additional evidence for the relationship between UAC and internal carbon pool $^{11}$. We measured the photosynthetic parameters $P_{2,000}$ and $P_{\max }$ of eight recently isolated strains using an oxygen electrode; $P_{2,000}$ is the photosynthetic rate at ambient $\mathrm{CO}_{2}$ availability and $P_{\max }$ is the maximum photosynthetic rate, which correlates with the $\mathrm{CO}_{2}$ availability at the site of isolation of each strain. The ratio of these two parameters provides a measure of the internal carbon pool (as explained in detail in Rickaby et al. ${ }^{11}$ ). We observed that high UAC content correlates with a large internal carbon pool (that is, high $P_{2,000} / P_{\max }$ ) (Fig. 3b, Supplementary Table 8 adapted from Rickaby et al. $\left.{ }^{11}\right)$. Therefore, it seems that $E$. huxleyi, have stopped varying in size (having reached a potential size 
minimum) in the modern ocean ${ }^{35}$, and instead they fine-tune their UAC content according to $p \mathrm{CO}_{2}$ availability in their local environment in order to achieve optimal calcification. This modern day adaptation would be equivalent to the geological strategy adopted over the millennia by the Coccolithales that have not changed in size and instead have been modulating their UAC in order to calcify efficiently despite the drop in their internal saturation state.

In conclusion, we propose CAPs as a promising new tool for the field of biogeochemistry. They are ancient molecules that, until today, have the same clear biological involvement in the calcification process of coccolithophores as they had millions of years ago $5,20,22$. They are preserved through time and can be successfully extracted in pure form from fossils and live cultures (Fig. 2a, Supplementary Figs 2 and 3). In addition, the UAC of CAPs can be used as a palaeoclimate proxy because it correlates with the internal saturation state of the coccolith vesicle and, for species with a weak or absent carbon concentrating mechanism, essentially reports on the change in environmental $p \mathrm{CO}_{2}$ (Figs $2 \mathrm{~b}$ and 3). Ultimately, this is almost a unique case where a biological signal goes hand-in-hand with climate change and provides us with an invaluable glimpse into the past.

\section{Methods}

Cultures and fossil material. Live species/strains used in this study were obtained from the Roscoff Culture Collection (www.sb-roscoff.fr/Phyto/RCC) and are listed in Supplementary Table 1. Cultures were grown in aged, filter-sterilized $(0.22 \mu \mathrm{m}$ Stericup-GP Filter Unit, Millipore) seawater enriched with trace metals, nitrate, phosphate and vitamins according to Probert and Houdan ${ }^{38}$, under $150 \mu \mathrm{mol} \mathrm{m}^{-2} \mathrm{~s}^{-1}$ illumination $\left(12 / 12 \mathrm{~h}\right.$ light/dark cycle) at $15^{\circ} \mathrm{C}$.

Fossil samples used in this study are listed in Supplementary Table 2. Fossil coccoliths from the last glacial inception $(\sim 107 \mathrm{ka})$ were isolated from sediments from the ocean drilling project (ODP) Site 1,123 in the Southern Pacific Ocean. A 30 g-fraction representing a time slice of $\sim 1,000$ years was separated into monospecific coccolith fractions according to Minoletti et al. ${ }^{39}$. The $<12 \mu \mathrm{m}, 10-12$ and $0-3 \mu \mathrm{m}$ fractions from this site were retained for further analysis. The same separation method was used to generate near mono-specific fractions of fossil coccoliths from the sediments obtained from the deep sea drilling project (DSDP) Site 588 in the Southwest Pacific. Four fractions of different age were retained $(8-20 \mu \mathrm{m}(\sim 12.4 \mathrm{Ma}) ; 12-20 \mu \mathrm{m}(\sim 13.6 \mathrm{Ma}) ; 8-10 \mu \mathrm{m}(\sim 14.5 \mathrm{Ma}) ; 10-12 \mu \mathrm{m}$ $(\sim 16.0 \mathrm{Ma}))$. Smear slides containing these samples were prepared and viewed under a cross-polarized light microscope and approximate relative numerical species abundances were determined by manual counts (Supplementary Table 3 and Supplementary Fig. 1). Bulk sediments from the Campanian, Late Cenomanian, Tithonian and Early Toarcian were pre-crushed and subsequently disaggregated in neutralized water by immersion in an ultrasonic bath $(30 \mathrm{~W}$ for $\sim 1 \mathrm{~h})$. The final suspension was allowed to settle and the supernatant was removed. Experiments described above were carried out in the Department of Earth Sciences (University of Oxford).

Scanning electron microscopy. Samples for SEM were filtered onto polycarbonate filters $(2.0 \mu \mathrm{m}$ pore size), rinsed with de-ionized water $(\mathrm{pH} 7.0)$, dried at room temperature for $24 \mathrm{~h}$, and sputter coated with gold-palladium. Imaging was performed with a Jeol JSM-840A SEM at $20 \mathrm{kV}$. Experiments described above were carried out in the Department of Earth Sciences (University of Oxford).

Extraction of polysaccharides. CAPs were extracted from cultured and sediment samples by modification of several protocols ${ }^{22,40,41}$. Harvested cells and sediments were cleaned with $1 \% \mathrm{v} / \mathrm{v}$ Triton X-100 and $4.5 \% \mathrm{v} / \mathrm{v} \mathrm{NaOCl}$ in $0.05 \mathrm{M} \mathrm{NaHCO}_{3}$. After the removal of organically bound matter, the samples were rinsed thoroughly with ultrapure water and stored at $-80^{\circ} \mathrm{C}$. Before extraction, the coccolith pellet was resuspended in $0.05 \mathrm{M} \mathrm{NH}_{4} \mathrm{HCO}_{3}$ by ultrasonication and the resulting suspension was further purified by centrifugation through a gradient of $100 \mathrm{ml}$ Ludox TM-50 colloidal silica layered with $25 \mathrm{ml} 20 \% \mathrm{w} / \mathrm{v}$ sucrose, at $23,000 \mathrm{~g}$ for $20 \mathrm{~min}$ at $4{ }^{\circ} \mathrm{C}$. The supernatant was discarded and the pellet was washed five times with $0.05 \mathrm{M} \mathrm{NH}_{4} \mathrm{HCO}_{3}$. Subsequently, the pellet was decalcified by incubating for $12 \mathrm{~h}$ in $0.5 \mathrm{M}$ EDTA $(\mathrm{pH} 8.0)$ at $4{ }^{\circ} \mathrm{C}$, followed by ultrasonication. Insoluble residues were removed by centrifugation at $31,000 \mathrm{~g}$ and the supernatant was buffer-exchanged into $20 \mathrm{mM}$ Tris $\mathrm{HCl}$ (pH 8.0) using a 10,000 MWCO Amicon Ultra-4 membrane (Millipore). The sample was then subjected to anion exchange liquid chromatography using a HiTrap DEAE FF (GE Healthcare) according to the manufacturer's instructions. The coccolith acidic polysaccharide (CAP) was eluted using $20 \mathrm{mM}$ Tris. $\mathrm{HCl}$ ( $\mathrm{pH} 8.0$ ), $0.5 \mathrm{M} \mathrm{NaCl}$, buffer-exchanged into ultrapure water and stored at $-20^{\circ} \mathrm{C}$. Experiments described above were carried out in the Department of Earth Sciences (University of Oxford).

Quantification of total polysaccharide and uronic acid. Polysaccharides were quantified using a phenol- $\mathrm{H}_{2} \mathrm{SO}_{4}$ assay ${ }^{42}$ with glucose as a standard. The UAC was determined using a modified carbazole- $\mathrm{H}_{2} \mathrm{SO}_{4}$ assay ${ }^{23}$ with glucuronic acid as a standard. The values obtained were normalized to $4 \mu \mathrm{g}$ total polysaccharide. Experiments described above were carried out in the Department of Earth Sciences (University of Oxford).

Electrophoresis of polysaccharides. Isolated CAPs were subjected to $12 \%$ PAGE and SDS-PAGE. $4 \mu \mathrm{g}$ of CAP were loaded on each lane. Alcian blue staining was carried out according to Møller et al. ${ }^{43}$. Briefly, gels were rinsed in wash solution $1\left(25 \% \mathrm{v} / \mathrm{v}\right.$ ethanol and $10 \% \mathrm{v} / \mathrm{v}$ acetic acid) for $1.5 \mathrm{~h}$ at $50{ }^{\circ} \mathrm{C}$ and, subsequently, stained with $0.1 \% \mathrm{w} / \mathrm{v}$ Alcian Blue $8 \mathrm{GX}$ in wash solution 1 for $15 \mathrm{~min}$ at $50^{\circ} \mathrm{C}$. The gels were de-stained by firstly rinsing with wash solution 1 for $15 \mathrm{~min}$ at $50^{\circ} \mathrm{C}$, and then with wash solution $2(10 \% \mathrm{v} / \mathrm{v}$ ethanol, $5 \% \mathrm{v} / \mathrm{v}$ acetic acid $)$ for $1.5 \mathrm{~h}$ at $50^{\circ} \mathrm{C}$ Experiments described above were carried out in the Department of Earth Sciences (University of Oxford).

Chromatographic analysis of polysaccharides. The samples $(100 \mu \mathrm{g}$ of extracted polysaccharide) were analysed by RP-HPLC using a Vydac C8 column (4.6 by $250 \mathrm{~mm} ; 5 \mu \mathrm{m}$ particle size) without a guard column on an Äkta purifier system (GE Healthcare). Samples were centrifuged at $16,000 \mathrm{~g}$ for $5 \mathrm{~min}$ to remove any insoluble material before the chromatography step. The elution buffers were: (A), $0.1 \%$ trifluoroacetic acid in ultrapure water; (B), $0.1 \%$ trifluoroacetic acid in acetonitrile. The column was equilibrated in buffer (A) at $2 \mathrm{ml} \mathrm{min}^{-1}$ at room temperature before injection of the sample. The running method involved the following steps: (1) linear increase to $20 \%$ buffer (B) over 4 min that was initiated at the moment of injection; (2) isocratic elution at $20 \%$ buffer (B) for $5 \mathrm{~min}$; (3) linear increase to $40 \%$ buffer (B) over $5 \mathrm{~min}$; (4) isocratic elution at $40 \%$ buffer (B) for $5 \mathrm{~min}$; (5) linear increase to $100 \%$ buffer (B) over $7.5 \mathrm{~min}$. The eluted compounds were detected by monitoring the absorbance of the polysaccharides at $230 \mathrm{~nm}$. The grey shaded areas of the eluted peaks (Supplementary Fig. 3) correspond to steps $3-5$ of the above method. Fifty micrograms of apple pectin (76,282, Sigma-Aldrich) were analysed by RP-HPLC, as above. The size exclusion chromatographic analysis of the G. oceanica RCC1314 CAP, was carried out by applying $100 \mu \mathrm{g}$ of polysaccharide to a Superdex 200 PC 3.2/30 column (GE Healthcare) pre-equilibrated in $50 \mathrm{mM} \mathrm{NaCl}$ at $0.1 \mathrm{ml} \mathrm{min}^{-1}$. Experiments described above were carried out in the Department of Department of Biochemistry (University of Oxford).

Data availability. All data supporting the findings of this study will be made available by the authors upon request.

\section{References}

1. de Vargas, C., Aubry, M.-P., Probert, I. \& Young, J. in Evolution of Primary Producers in the Sea (eds Falkowski, P. \& Knoll, A. H.Ch. 12Elsevier Academic, 2007).

2. Young, R. Y. \& Henriksen, K. Biomineralization within vesicles: the calcite of coccoliths. Rev. Mineral. Geochem. 54, 189-215 (2003).

3. Westbroek, P., de Jong, E. W., Dam, W. \& Bosch, L. Soluble intracrystaline polysaccharides from coccoliths of Coccolithus huxleyi (Lohmann) Kamptner. Calcif. Tiss. Res. 12, 227-238 (1973).

4. Borman, A. H. et al. The role in $\mathrm{CaCO}_{3}$ crystallization of an acid $\mathrm{Ca}^{2+}$ binding polysaccharide associated with coccoliths of Emiliania huxleyi. Eur. J. Biochem. 129, 179-183 (1982).

5. Kayano, K., Saruwatari, K., Kogure, T. \& Shiraiwa, Y. Effect of coccolith polysaccharides isolated from the coccolithophorid, Emiliania huxleyi, on calcite crystal formation in in vitro $\mathrm{CaCO}_{3}$ crystallization. Mar. Biotechnol. 13, 83-92 (2011).

6. Borman, A. H. et al. Coccolith-associated polysaccharides from cells of Emiliania huxleyi (Haptophyceae). J. Phycol. 23, 118-123 (1987).

7. Henriksen, K. \& Stipp, S. L. S. Controlling biomineralization: the effect of solution composition on coccolith polysaccharide functionality. Cryst. Growth Des. 9, 2088-2097 (2009).

8. Fichtinger-Schepman, A. M. J., Kamerling, J. P., Versluis, C. \& Vliegenthart, F. G. Structural studies of the methylated, acidic polysaccharide associated with coccoliths of Emiliania huxleyi (Lohmann) kamptner. Carbohydr. Res. 93, 105-123 (1981).

9. Marsh, M. E. Regulation of $\mathrm{CaCO}_{3}$ formation in coccolithophores. Comp. Biochem. Phys. B 136, 743-754 (2003).

10. Ozaki, N. et al. Structural and functional diversity of acidic polysaccharides from various species of coccolithophorid algae. Thalassas 20, 59-68 (2004).

11. Rickaby, R. E. M. et al. Environmental carbonate chemistry selects for phenotype of recently isolated strains of Emiliania huxleyi. Deep Sea Res. Pt. II 127, 28-40 (2016). 
12. van Bleijswijk, J. et al. Distribution of two types of Emiliania huxleyi (Prymnesiophyceae) in the Northeast Atlantic Region as determined by immunofluorescence and coccolith morphology. J. Phycol. 27, 566-570 (1991).

13. Giuffre, A. J., Hamm, L. M., Han, N., De Yoreo, J. J. \& Dove, P. M. Polysaccharide chemistry regulates kinetics of calcite nucleation through competition of interfacial energies. Proc. Natl Acad. Sci. 110, 9261-9266 (2013).

14. Liu, H., Aris-Brosou, S., Probert, I. \& de Vargas, C. A time line of the environmental genetics of the Haptophytes. Mol. Biol. Evol. 27, 161-176 (2010).

15. Henderiks, J. \& Rickaby, R. E. M. A coccolithophore concept for constraining the Cenozoic carbon cycle. Biogeosciences 4, 323-329 (2007).

16. Bollman, J., Baumann, K.-H. \& Thierstein, H. R. Global dominanace of Gephyrocapsa coccoliths in the late Pleistocene: selective dissolution, evolution, or global environmental change? Paleoceanography 13, 517-529 (1998).

17. Young, J. et al. A guide to extant coccolithophore taxonomy. Special issue. J. Nannoplankton Res. 1, 1-125 (2003).

18. Young, J. R. \& Westbroek, P. Genotypic variation in the coccolithophorid species Emiliania huxleyi. Mar. Micropaleontol. 18, 5-23 (1991).

19. Beaufort, L. et al. Sensitivity of coccolithophores to carbonate chemistry and ocean acidification. Nature 476, 80-83 (2011).

20. Sand, K. K. et al. Biomineralization: long-term effectiveness of polysaccharides on the growth and dissolution of calcite. Cryst. Growth Des. 14, 5486-5494 (2014).

21. Corstjens, P. L. A. M. et al. GPA, a calcium-binding protein in the coccolithophorid Emiliania huxleyi (Prymnesiophyceae). J. Phycol. 34, 622-630 (1998).

22. de Jong, E. W., Bosch, L. \& Westbroek, P. Isolation and characterization of a $\mathrm{Ca}^{2+}$-binding polysaccharide associated with coccoliths of Emiliania huxleyi (Lohmann) kamptner. Eur. J. Biochem. 70, 611-621 (1976).

23. Cesaretti, M., Luppi, E., Maccari, F. \& Volpi, N. A 96-well assay for uronic acid carbazole reaction. Carbohyd. Polym. 54, 59-61 (2003).

24. Schroeder, D. C. et al. A genetic marker to separate Emiliania huxleyi (Prymnesiophyceae) morphotypes. J. Phycol. 41, 874-879 (2005).

25. Bendif, E. M. et al. Genetic delineation between and within the widespread coccolithophore morpho-species Emiliania huxleyi and Gephyrocapsa oceanica (Haptophyta). J. Phycol. 50, 140-148 (2014).

26. Anning, T., Nimer, N., Merett, M. J. \& Brownlee, C. Costs and benefits of calcification in coccolithophorids. J. Marine Syst. 9, 45-56 (1996).

27. Bolton, C. T. \& Stoll, H. M. Late Miocene threshold response of marine algae to carbon dioxide limitation. Nature 500, 558-562 (2013).

28. Hermoso, M., Horner, T. J., Minoletti, F. \& Rickaby, R. E. M. Constraints on the vital effect in coccolithophore and dinoflagellate calcite by oxygen isotopic modification of seawater. Geochim. Cosmochim. Acta 141, 612-627 (2014)

29. Sekino, K. \& Shiraiwa, Y. Accumulation and utilization of dissolved inorganic carbon by a marine unicellular coccolithophorid Emiliania huxleyi. Plant Cell Physiol. 35, 353-361 (1994).

30. Nimer, N. A. \& Merrett, M. J. The development of a $\mathrm{CO}_{2}$-concentrating mechanism in Emiliania huxleyi. New Phytol. 133, 383-389 (1996).

31. Paasche, E. A review of the coccolithophorid Emiliania huxleyi (Prymnesiophyceae), with particular reference to growth, coccolith formation, and calcification-photosynthesis interactions. Phycologia 40, 503-529 (2001).

32. Shiraiwa, Y. Physiological regulation of carbon fixation in the photosynthesis and calcification of coccolithophorids. Comp. Biochem. Physiol. 136, 775-783 (2003).

33. Stojkovic, S., Beardall, J. \& Matear, R. $\mathrm{CO}_{2}$-concentrating mechanisms in three southern hemisphere strains of Emiliania huxleyi. J. Phycol. 49, 670-679 (2013).

34. Langer, G. et al. Species-specific responses of calcifying algae to changing seawater carbonate chemistry. Geochem. Geophy. Geosy. 7, Q09006 (2006).

35. Henderiks, J. \& Pagani, M. Coccolithophore cell size and the Paleogene decline in atmospheric $\mathrm{CO}_{2}$. Earth Planet Sci. Lett. 269, 575-583 (2008).

36. Henderiks, J. Coccolithophore size rules-reconstructing ancient cell geometry and cellular calcite quota from fossil coccoliths. Mar. Micropaleontol. 67, 143-154 (2008)

37. Hannisdal, B., Henderiks, J. \& Lee, H. L. Long-term evolutionary and ecological responses of calcifying phytoplankton to changes in atmospheric $\mathrm{CO}_{2}$. Glob. Change Biol. 18, 3504-3516 (2011).

38. Probert, I. \& Houdan, A. in Coccolithophores: From Molecular Processes to Global Impact (eds Thierstein, H. R. \& Young, J. R.) (Springer, 2004).

39. Minoletti, F., Hermoso, M. \& Gressier, V. Separation of sedimentary micronsized particles for palaeoceanography and calcareous nannoplankton biogeochemistry. Nat. Protoc. 4, 14-24 (2009).
40. Marsh, M. E., Chang, D.-K. \& King, G. C. Isolation and characterization of a novel acidic polysaccharide containing tartrate and glyoxylate residues from the mineralized scales of a unicellular coccolithophorid alga Pleurochrysis carterae. J. Biol. Chem. 267, 20507-20512 (1992).

41. Kayano, K. \& Shiraiwa, Y. Physiological regulation of coccolith polysaccharide production by phosphate availability in the coccolithophorid Emiliania huxleyi. Plant Cell. Physiol. 50, 1522-1531 (2009).

42. Hodge, J. E. \& Hofreiter, B. T. in Methods in Carbohydrate Chemistry Vol. 1 (eds Whistler, R. L., Wolfrom, M. L., BeMiller, J. N. \& Shafizadeh, F.) (Academic Press, 1962).

43. Møller, H. J., Heinegård, D. \& Poulsen, J. H. Combined alcian blue and silver staining of subnanogram quantities of proteoglycans and glycosaminoglycans in sodium dodecyl sulfate-polyacrylamide gels. Anal. Biochem. 209, 169-175 (1993).

44. Royer, D. L. $\mathrm{CO}_{2}$-forced climate thresholds during the Phanerozoic. Geochim. Cosmochim. Acta 70, 5665-5675 (2006).

45. Park, J. \& Royer, D. L. Geologic constraints on the glacial amplification of Phanerozoic climate sensitivity. Am. J. Sci. 311, 1-26 (2011).

46. Beerling, D. J. \& Royer, D. L. Convergent Cenozoic $\mathrm{CO}_{2}$ history. Nat. Geosci. 4, 418-420 (2011).

47. Hönisch, B. et al. The geological record of ocean acidification. Science 335, 1058-1063 (2012).

48. Lüthi, D. et al. High-resolution carbon dioxide concentration record 650,000-800,000 years before present. Nature 453, 379-382 (2012).

\section{Acknowledgements}

We are grateful to M. Hermoso for sediment samples from the Early Toarcian, H.C Jenkyns for sediment samples from the Late Cenomanian and Tithonian, and S.A. Robinson for sediment samples from the Campanian. We would like to thank A.M.C. Heureux and M. Hermoso for their help with the algal cultures, J.S. Hirst for size separating the Neogene samples and extracting the CAPs from the retained fractions, and C. Anderson for initial discussions. We are grateful to Station Biologique de Roscoff for providing us with the cultures used in this work. This work was jointly funded by the UK Ocean Acidification Research Programme, NERC (NE/HO17119/1) (to R.E.M.R), the European Research Council (SP2-GA-2008-200915) (to R.E.M.R), the Philip Leverhulme Trust (to R.E.M.R) and an MRC Career Development Award (MR/M009505/1) (to D.A.I.M.).

\section{Author contributions}

R.B.Y.L. and R.E.M.R. designed research; R.B.Y.L., D.A.I.M., G.P. and H.L.O.M. performed research; R.B.Y.L., D.A.I.M., G.P. and H.L.O.M. analysed data; R.B.Y.L., D.A.I.M. and R.E.M.R. wrote the paper with input from all authors.

\section{Additional information}

Supplementary Information accompanies this paper at http://www.nature.com/ naturecommunications

Competing financial interests: The authors declare no competing financial interests.

Reprints and permission information is available online at http://npg.nature.com/ reprintsandpermissions/

How to cite this article: Lee, R. B. Y. et al. The uronic acid content of coccolithassociated polysaccharides provides insight into coccolithogenesis and past climate. Nat. Commun. 7, 13144 doi: 10.1038/ncomms13144 (2016).

Publisher's note: Springer Nature remains neutral with regard to jurisdictional claims in published maps and institutional affiliations.

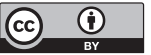

This work is licensed under a Creative Commons Attribution 4.0 International License. The images or other third party material in this article are included in the article's Creative Commons license, unless indicated otherwise in the credit line; if the material is not included under the Creative Commons license, users will need to obtain permission from the license holder to reproduce the material. To view a copy of this license, visit http://creativecommons.org/licenses/by/4.0/

(C) The Author(s) 2016 